\title{
12. Functional Dystopia: Diversity, Contestability and New Media in the Academy
}

Jenny Corbett, Andrew MacIntyre and Inger Mewburn

\section{Introduction}

Many scholars in the Social Sciences today are concerned that growing pressures for applied or policy-relevant research, and the importance placed on external research funding, are having systemically negative influences upon academic life. Academics generally are expressing concern that reduced public funding, more reliance on student fees as the mainstay of revenue and a rise in 'managerialism' in response to closer regulatory scrutiny, divert universities from their core business and traditional values. Our view is more positive. We make three arguments to this effect. First, we believe implicit comparisons with a notional happier past are themselves problematic. Secondly, the multiplicity of funding sources now underwriting academic research has created greater contestability in the market for ideas - something we believe is strongly positive. Thirdly, while there are certainly unwelcome constraints on researchers at the margins of casual employment (a growing portion of the academic population), we do not see increasing marketisation and the rise of new technology as necessarily oppressive - indeed, they can generate new modes of academic practice. In this chapter, we offer a preliminary sketch of our main contentions, rather than a detailed elaboration and defence.

In the first section of the chapter, we address the myth of a golden age of university independence. To many it feels as if along with changed, and generally tighter, funding, has come a greater demand for accountability and scrutiny plus an uncomfortable exposure to competitive market pressures even though the social 
value of education means that it cannot be judged solely by economic criteria. But the evidence of history and international comparison tells a different story. The balance between external intervention and academic independence changes over time and place. If the immediate post-Second World War period was one of relatively relaxed oversight of universities, accompanied by a belief in the role of governments to provide public goods and rebuild cultural and social capital in the Anglo-Saxon world, that was specific to a time and place in history. It was not a norm and it is no longer the basis for realistic policy. Nostalgia for a particular historical moment can create myopia and confused thinking.

In the next section we weigh the disadvantages of less certainty of funding against the advantage of independence from a single source of support. Over the last two decades we have certainly witnessed a changing balance in sources of funding, with increasing importance of student fees and the associated pressure for responsiveness to student preferences. Alongside this has been a surge in regulatory controls on government research funding schemes together with the growing importance of contract and consultancy funding for research. Combined, factors of this sort generated sharp concerns within the academic community ranging from perceived rampant managerialism and excessive commercialisation, to degradation of scholarly independence (Ginsberg 2011; Hil 2012; Nussbaum 2010; Thornton 2008, 2009). As we will discuss, while funding changes have certainly brought challenges, such arguments understate the fact that reduced reliance on a single source of funding can bring advantages of increased contestability and independence.

In the final section, we note the exciting opportunities brought by new technology. Coupled with the changes in funding sources and accountabilities is the growth of new technology and digital media, particularly social media and content-management systems that enable educational materials - once the closeted preserve of the individual professor who hiked across campus with their slide carousel - to be released, open and free of charge on the internet via large, corporate providers such as EdX and Coursera. This trend, which Weller (2011) calls a turn to the 'pedagogy of abundance', signals a world where, as he points out, talent is no longer scarce or hard to locate, content has been translated from the slide deck to intangible (and infinitely transportable) 'bits', available on demand 24 hours a day to a global audience.

In conclusion, we do not entirely disagree with the many who have pointed out the damage - even violence - these technological and workplace changes have done to traditional notions of academic identity and freedom - but we take a tempered view and hope to move the debate beyond this stage. Clegg (2008) outlines a range of responses to what she calls (after Barnett 2003) 'pernicious ideologies' of the contemporary university, including quality and audit controls, the 'seemingly malign influence of managerialist practices', consumerism and 
undermining of autonomy and respect for academics and their work. There is a large and growing body of literature that identifies (and bemoans) the 'casualisation' of the academic workforce. Kimber (2003) claims that structural changes in Australia have brought into being a two-tiered system with a 'tenured core and a tenuous periphery' and the end of clear career paths for academics. This literature has had little, if any, tangible effect on changing the workplace practices it criticises. It is clear that new lines of critique need to be developed, ones that acknowledge growth, increasing complexity and change as ever present and inevitable within our universities, and recognise the new possibilities they raise.

Well-reasoned, elegantly-argued critiques, as valid as we think they are, have not been accepted by politicians and the public. In part, it must be acknowledged, this is a product of the chronic obstacles to university leaders speaking with a strong and unified voice. More broadly, too often academics come across in the media as seeking to preserve entitlements in an era when others are having to go without job certainty or the ability to pursue the work they really want to do. Why should academics and universities be treated differently? This is a hard argument to counter and one that has not been well served by much of the analysis to emerge from universities themselves. We do not answer those questions here but we do bring an understanding of the role of the new in the contemporary university to bear on these old problems.

\section{The myth of the golden age}

In their entertaining history of The Australian National University (ANU), Foster and Varghese (2009) paint a picture of the Honourable John Dedman laying the foundation stone of University House on the 24 October 1949. The then Vice-Chancellor of ANU, Sir Douglas Berry Copland, sitting in the audience, listened to a speech that would have warmed the heart of any contemporary vice-chancellor. The university, opined Dedman, should continue to operate without the messy intrusion of party politics. Free to pursue knowledge for the highest purpose, said the minister, ANU should have no strings attached to its income, other than in the broadest terms. ViceChancellor Copland leaned over, so the story goes, to congratulate Dedman's boss, Prime Minister Ben Chifley, on this fine speech from his minister. We can only imagine Copland's chagrin when Chifley treated him to a dose of cold, hard political reality.

Yes, it was a great speech, Chifley agreed, but the trouble with Minister Dedman was 'he really believes it' (Foster and Varghese 2009, 114). 
The little vignette is telling: from almost the first moment the national university was tangled up in politics - as are all Australian universities and most others around the world. This is also a reminder that some of the discussion about what is wrong with universities today may be guilty of nostalgia for a mythical golden age of the university, when individual scholars engaged in uninterrupted creative thought on deep questions of their own devising, free of external oversight. Furthermore, the backward-looking argument that we should return to a time that was more conducive to academic life is unlikely to be helpful in considering whether we now have the right policy settings to get us where we need to be. Contemporary universities' tasks are complex, with objectives ranging from technical and vocational training to solving the moral and practical challenges of our age by brave, iconoclastic thinking, sometimes within the same institution. Inevitably, this means that in defining 'what universities are

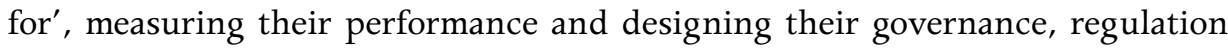
cannot be easy. Any pursuit of single, standardised models by either academics or government will be quite problematic.

Marginson and Considine (2000) outline new trends in governance structures which include the rise of executive power and corresponding decline of 'disciplinary' (academic) power to set priorities and direction for academic work. However, the problem of the modern 'multiversity', as Collini (2012) dubs it, has old roots - there never was a golden age when universities were pure seats of higher learning unfettered by the demands of practical masters, whether church or state. Governments have, for centuries now, pulled the university's strings all around the world. The desire by the paymasters to exert 'remote control' over what academics do and how they do it is nothing new. In his book, Academic Charisma and the Origins of the Research University, Clark (2006) discusses the German system of the late Enlightenment, from which we draw many of our academic traditions, including the PhD. Clark cites the work of Johann Justi from the 1760s, whom he calls the 'Adam Smith of Prussian "police science"" (what today might be called political science). Justi noticed that the academics of his time tended to ignore financial rewards and he stressed the need for academics to have the freedom to pursue their work in the way they saw fit - so long as these aligned with the needs of the state. Justi foreshadowed the role of higher education auditing agencies, such as the Tertiary Education Quality and Standards Agency (TEQSA). As Clark $(2006,12)$ puts it, Justi argued that:

The state must set up inspectors for wares, as well as a system of seals or labels to indicate ranges of excellence in products. When the state notices that some products, including academic ones, are inferior, then prizes and payments ought to be instituted to encourage invention. 
In a move that echoes contemporary public servants carrying out government objectives from within an education department, Justi argued that, if needs be, external experts should be brought in to enforce these standards, since 'for money one can attain anything' $(2006,12)$. The practice of oversight on academic work pre-dates even the beginnings of the 'police state' in northern Europe. Clark outlines the processes behind 'visitations' of the clergy to the proto-university cathedral schools in the 13th and 14th centuries. The visitation practice involved senior bishops and officials travelling around the countryside inspecting the conduct of teachers and monks and looking for 'improvement' since their last visit. Interestingly, there is evidence that these early academics resisted such audit-like practices. Clark claims that the visitations to Franciscan foundations in 1232 and 1239 'appeared so inquisitorial that the poor friars took the visitors for spies and hated them' $(2006,341)$.

Clearly, we cannot plausibly hark back to a golden age when the state, or the church, provided unlimited funding and left us alone to pursue whatever 'pure' research we wanted and when students studied whatever we told them to. Life was never thus. And we also cannot champion such a system and, having been left alone to develop new lines of enquiry and fields of research and make remarkable discoveries, then be appalled by the fact that the users of research increasingly want to engage with the production of research both inside and outside universities.

Within universities too, simplistic thinking about 'value-free', 'pure' research is surely a thing of the past. The self-aware researcher recognises that there is, and should be, a constant struggle about how much our inherited norms enter all academic work. At what point does the mainstream way of thinking become an impediment to originality and what is the fate of the iconoclast who challenges too soon? There is no right answer about who should choose the questions for research or how they should be researched. A subject is not made irrelevant or illegitimate for academic study because a policymaker (or the Queen) poses the question. The danger is when the pursuit of apparently 'irrelevant questions' (i.e. not immediately of practical relevance) is blocked. But in fact current critics overstate this danger: present policy settings in Australia, particularly those concerned with ERA research assessment and impact, for the most part do almost the opposite. They do not reward media professors and impact does not, in any of the variants, mean being on TV responding to the issues of the moment with no underlying research evidence. The new regulatory, management and governance regimes are not killing the culture of academia - but they are certainly changing it; for the worse in some respects and for some individuals, but also for the better. Most of us would agree that regulatory change that 
reduces male and white privilege is a positive step, as are checks to ensure minimal teaching standards and the transparent storage of scientific data to facilitate experimental replicability.

This historical perspective is important in considering the cocktail of pressures facing Australian and other higher education sectors: tight public funding, increased regulation, greater competition for students, faculty and professional staff, together with major technological change. As Sharrock $(2012,324)$ points out, institutional leaders 'must handle a Rubik's cube of Rubik's cubes', where growth in the size and complexity of institutional management has resulted in 'elaborate systems' which are required to manage (and report on) the activities of the contemporary university. As Sharrock puts it $(2012,323)$, universities face the 'eternal strategic dilemma of infinite mission and finite means' without the 'avuncular mix of funded growth, low competitive pressure and loose performance expectations, which characterised the 1970s'.

Our quick tour of the history of universities shows that while these are not new pressures, it is now more clearly understood by academics and private citizens (who are increasingly consumers of higher education) that the multiplicity of functions of universities leads to a variety of outcomes that represent both private and public benefits. The public benefit, while hard to define in developed countries (easier to demonstrate in developing ones where the impact on growth is clear), is not completely dismissed in principle even by the most ardent managerialist free-marketeer, though its scale is contested. It underpins the case for some element of public funding for at least part of the higher education sector. The private benefit to individual recipients of university education (in terms of generally higher salaries for graduates than non-graduates) is similarly not disputed but its value, too, is much debated, leading to dispute about how much the user should pay. The very complexity of the university as a contemporary institution adds to the difficulty of knowing whether universities are 'doing their job' and who should pay.

\section{Funding and freedom}

If ongoing change in the university sector is a constant, one of the most widely discussed dimensions of recent change is the funding of universities. As former Stanford University President Gerhard Casper $(2010,1)$ has put it, 'these are the best of times and worst of times for universities'. These are the best of times as, almost everywhere, the dominant discourse is of the centrality of universities in a globalised knowledge economy. And these are also the worst of times especially for public universities, 'because as governments face extraordinary budget shortfalls due to their spendthrift ways and the sharp economic recession, 
they do not generally assign higher education and research funding the priority that their emphasis on innovation would suggest. They do not put their money where their mouth is.'

The recent circumstances sharpen the old question of the value of the university, which matters because it affects societies' views of who should pay for universities. The economic view that beneficiaries should pay is 'incentive compatible' and therefore efficient. This means that those who benefit have an incentive to pay for the service and, if the provider fails to deliver, to cut their support or vote with their feet. That is why the argument has become influential in global policy circles. The logic is correct but there is a big risk that the public benefit of universities is undervalued, with the result that too little overall investment is made, since private beneficiaries will not pay for the public externalities. This is one, but not the only, fear of those who decry the move to 'co-payment' by students (the other being fairness and impact on poorer students). Another concern about heavy reliance on student fee income is that the academic purpose will be distorted (deflected) towards the demands of 'customers' who, in the extreme view, do not really know what is important and valuable in the enterprise in which they are engaged.

At the same time the opposite fear, that publicly-funded universities will be interfered with and misdirected towards activities determined by the paymasters (governments - and ultimately tax payers), is often voiced by the same critics. By implication, there is some other world in which universities are funded by benefactors who require no accountability and who express no views about what universities should do. As Capano (2011) shows, across a range of different models of university governance, the one constant is a continually changing balance between government or market control and the 'independence' of the university. Yet the plethora of models still produces quality outcomes assessed against objectives of increasing access (student numbers), original research, technical advances and economic benefits. No single governance or funding model, it seems, outperforms all others. While there are some global common trends, there is no convergence. This does not imply that governance and funding models are irrelevant but that we need to look elsewhere to understand what makes great universities and what kind of interference inhibits them.

In Australia, we are currently seeing the generalised phenomenon of funding pressure played out starkly. Indeed, if anything, Australia has been out of step with other wealthy countries in that government funding for universities in general, and research in particular, has actually increased in recent years (Commonwealth of Australia 2011, 17-8). We are now moving painfully into the very much tighter budgetary circumstances of many other countries. No less 
contentious than the issue of the quantum of government funding is the profile or character of funding. A recent Group of Eight discussion paper $(2013,4)$ sets the matter out clearly:

... many universities are operating in a funding environment that requires them to become more responsive to the immediate needs of business or society, a situation exacerbated by the growing cost of research and the increased reluctance of all funding bodies to pay the full costs of the research they commission. In seeking financial support from a broader range of sources, universities are coming under pressure to produce short-term practical outcomes, to commercialise, and to chase funding, no matter what the implications of winning it ...

Taken to its extreme, this approach could prevent universities from making their really significant, fundamental contributions to economic, social and cultural development or environmental sustainability; and could ultimately lead to more fragile and less resilient societies.

We agree with this assessment. However, we also believe that the current situation is not as bad as often depicted and need not necessarily be taken to anything like its possible extreme. There can be little doubt that, other things being equal, the greater a university's dependence on short-term funding, the less the scope for the type of research that requires sustained independent scholarly inquiry. This is a particular challenge in the physical and natural sciences, given the typically high infrastructure costs and multi-investigator projects, but is nonetheless a challenge too for the social sciences.

Certainly we must ask to what extent the expanding phenomenon of contract grants and consultancy work is compromising the character and independence of scholarly research. While it is true that some entities commissioning research seek to define very tightly the subject of research work, its outcomes and even ownership, this is not a universal phenomenon. Indeed, our personal experience and wider anecdotal evidence suggests a growing awareness on the part of research-funders of the changing dynamics and challenges of the contemporary university environment.

For instance, there appears to be widespread recognition among government agencies that the era of education and/or science and technology ministries adequately funding the full range of research needs is long past. Specialised agencies right across the public spectrum are increasingly reaching out to universities and investing in multi-year agreements in order to stimulate research. We have experienced this with agencies ranging from social security to finance, from environment to defence, from international development assistance to taxation. In our experience, the primary motivation of the funding agency is very often to sponsor new and creative thinking. It is precisely the independent and uncontrolled nature of academic thinking they are seeking to fund; they 
have highly educated staff of their own (not infrequently with doctorates), but these staff think and work within the tightly specified incentive structures and hierarchies of officialdom.

Furthermore, prospective funding agencies are drawn not just to the reality of independent analysis, but also to the perception and prestige of independent analysis, for the powerful legitimating benefits this can bring to their intramural policy battles within the government sector as well as their efforts to lead public thinking on particular issues. So strong is the interest of government agencies across the spectrum that not only are they increasingly prepared to invest substantial sums from their own operating budgets, but they are writing funding agreements specifically delegating very high levels of research independence to the scholars involved: for example, only designating a minor portion of the budget for research on topics requested by the funder - with the rest explicitly at the discretion of the researchers. Speaking again from our direct experiences and those reported by colleagues in other universities, somewhat surprisingly, investments in research from the business sector seem to come with, if anything, fewer - rather than more - strings attached. In part this is likely to be a function of stricter reporting and accountability requirements on the use of public money and the greater freedom that businesses have to decide on the use of their own money. But we have also experienced remarkably enlightened thinking among corporate decision-makers about the importance of independent and long-range scholarly research capabilities and a preparedness to mobilise funds in support of it.

The advent of new technology raises the intriguing question of whether we could think more broadly about what constitutes a funding base. Could we use the internet as an additional strategy to widen funding for academia and academics, and loosen the grip of funders with other agendas? The experiment in research crowdsourcing by Deakin University is an interesting development. Here researchers make a pitch directly to the public to fund research for its intrinsic worth. Some might see this kind of private money from citizens as more 'pure' than the national priorities of the government or donations from large private companies.

As this chapter was being written, Deakin University researchers were trialling the use of Pozible.com, a crowd-funding site, to generate seed funding for short research projects. The 'kick backs' to the crowd-funders are transparent on the site. Along with a 'pitch' explaining the value of the research was a clear outline of what you could expect for a $\$ 2, \$ 30$ and $\$ 50$ donation. The project, led by Professor Deborah Verhoven with a multi-disciplinary team, concentrated on 
enhancing the researchers' social media strategies, thus building an 'audience' for their research both with social media. Of the seven projects which pitched through Pozible.com, six reached their funding targets. ${ }^{1}$

However exciting the Pozible work done by Deakin is, for now, the most desirable position for a university is to have a large portion of its resource base being made up of reliable longer-term funding. This underpins its ability to recruit and retain the most sought-after scholars and house them within a critical mass of intellectually diverse colleagues who can sustain long-term data-gathering, debate and theoretical inquiry. But given that such funding is becoming scarcer in relative terms, universities and individual academics are seeking alternative forms of funding in an effort to improve their ability to pursue institutional and individual academic objectives.

We certainly do not mean to suggest that there is a readily accessible and abundant supply of 'academic-friendly' research funding waiting to be harvested. Nor are we under any illusion that a substantial (if unspecified) portion of contract-type research funding does not come with very significant controls. And, above all, we are acutely mindful of the heightened challenge presented by contract-type funding to the prestige of universities if individual academics leave themselves open to the perception and reality of material conflicts of interest by failing systematically and proactively to publicise their sources of funding. But these considerations notwithstanding, we do maintain that this new funding frontier is much less bleak than often portrayed and, moreover, is one that, as both individual scholars and university officers, we approach with a good deal of optimism.

Finally, we also contend that there is something inherently healthy - in terms of academic vitality - to greater diversity of funding sources and greater contestability of these sources. Put differently, while a core of predictable longerterm funding is a necessary ingredient for universities, we do not believe the quality and independence of research is maximised by that funding all coming from a single Ministry of Education-type source. The examples of leading North American public and private universities are one illustration of this. What matters is that there needs to be reasonable predictability about resource flows over the medium to long term, and a multiplicity of contestable funding sources is probably a preferable option. It is the task of university leaders to navigate these waters and assist individual academics - whether privileged with a tenured appointment or not - in seeking the resources they need to pursue their research ambitions.

1 Deakin University. Retrieved 17 December 2013, from http://t.co/8dTkcLslfq. 


\section{Marketisation and technology}

No investigation of change in Higher Education would be complete without an examination of new technologies, which open up unexpected opportunities for innovation. Of particular interest is the group of interactive technologies collectively called Web 2.0. These include social media and cloud-based technologies, which together bring the means of production of academic 'stuff' back into the hands of the academic who no longer needs access to large enterprise systems to do authoring and distribution of content. Free online tools enable academics to craft teaching material, generate research data, and share knowledge and expertise on cloud-based, open-sourced software platforms.

With this kind of control over the means of production - and access to the public as direct sponsors of research - academics truly can become 'technopreneurs': making, sharing, remixing and even selling their academic expertise in a worldwide market. For example, the academic who makes a blog and builds an audience may leverage this social media reach by selling books, downloadable resources or their services, as speakers and teachers.

Building academic peer networks also becomes easier in this online environment. The conference circuit used to be the primary vehicle for academics to meet and build relationships outside their institutions; social media sites like Twitter enable peers with mutual interests to meet and build relationships without the cost of an airfare. These peer networks echo existing academic cultures in that they tend to be reciprocal and rely on a common understanding of an academic 'gift economy' (Mewburn and Thomson, 2013). This is most visible on platforms like Twitter where information 'bundles' are offered and taken up on an ad hoc basis and, over time, operate to build networks of trust online (often dominated by a number of opinion leaders). The kind of literacies required for casual academics to take advantage of these new spaces of opportunity are different from those which were required prior to the turn of the century, when many tenured academics entered the academy.

The 'publish or perish' mantra is increasingly being replaced with the imperative to 'be visible or vanish' (thanks to Dr John Lamp for this phrase). However, there may not yet be general recognition within the academic community of this imperative.

What way forward for the individual - and the academy - in such a world? In Gutenberg to Zuckerberg, John Naughton points out that we are bad at predicting the disruptive impact of technology. Although bibles were the first things cranked out on Gutenberg's new printing press, the Catholic Church 
ended up the loser in that particular industrial revolution. Naughton argues that, especially when it comes to technology, we can over-emphasise some changes and entirely miss others.

We are just entering the age of a 'post scarcity' academic economy, characterised by what Weller (2011) deems a 'pedagogy of abundance'. Massive open online courses (MOOCS), which make it possible to access educational material and techniques from premier institutions without paying, challenge the very business model of the university itself. Another challenge is presented in the form of 'micro-credentialism' such as Mozilla's open badges project. Open badges are essentially bits of code that can be issued by anyone (individuals or institutions) to individuals as recognition for participation in learning activities and the attainment and demonstration of skills. Given that there is plenty of teaching and learning material online available for free (including, but in no way limited to, MOOCs), open badges are a way to create a legible learner identity without a singular institution to do the credentialing work.

To see the marketisation of the academy as something to be resisted risks wiping out these new spaces of innovation, which are breeding forms of academia that may help the academy survive the coming abundance crisis. There is obvious potential for conflict between our scarcity model and the abundance of online spaces. Micro-credentialing such as open badges, which turn anyone into an education provider, holds the potential to seriously disrupt our current business model. As the technology commentator and blogger Clay Shirky points out, Napster didn't kill the old music industry - it was the idea of Napster (that you can get just one track, whenever you want, online), that contributed to the collapse of an entire industry. It wasn't the technology, Shirky (2012 blog) is at pains to point out, that is the real issue here - it is the failure of imagination of those within the industries being threatened by new technology. The music industry:

... just couldn't imagine - and I mean this in the most ordinarily descriptive way possible - could not imagine that the old way of doing things might fail. Yet things did fail, in large part because, after Napster, the industry's insistence that digital distribution be as expensive and inconvenient as a trip to the record store suddenly struck millions of people as a completely terrible idea.

Journalists are dealing with the disruptive effects of an abundance economy in the form of 'new media' - academics are just late to the digital party. One thing we can learn from the industries that have gone before us is that those who do not embrace change may die. 


\section{Conclusions}

What does the debunking of the myth of the golden age, when academia basked in unlimited funding with no strings attached (or at least an avuncular laxity in paying the bills), and a harder look at the pros and cons of diversified funding and the 'marketisation' of the university, tell us about the sense of crisis and frustration that so many academics claim to feel? Principally it suggests that universities and the subjects they research and teach constantly change. There are no 'right' structures to decide what are appropriate subjects for academic study and inclusion in university syllabi. Questions about the value of any particular discipline to the modern university or to society at large (such as the recent attacks on the Humanities and the value of pure and applied Social Science research) come and go and are not closely connected to funding or governance structures. They occur in both publicly- and privatelyfunded systems and require thoughtful and constant explication and rebuttal. Academic inquiry inevitably leads to questioning the questions, so that new fields of study emerge and their emergence is testimony to the health of the institutions. Designing management and governance structures which allow that to happen is critical to both the wealth-creation and intellectual functions of universities. As in any other field of regulation, regulators will always be one step behind the innovators. Social science, as researched today, was not conceived in the mediaeval university yet it owes its origins to the then core disciplines of moral philosophy, mathematics and the study of the natural world (see, for example, de Ridder-Symoens 2003). Is it useful? That depends on what we think we need to know now. Its full value will probably not be known until the next set of questions emerges and new fields evolve.

If our current solutions to these issues are 'managerialist' and narrow-minded (as some believe), they are already under challenge from new technologies. These put tools in the hands of newer entrants to the academy with power that is not yet fully clear and is certainly underestimated or feared by many entrenched incumbents. Contestability of ideas and challenge to the traditional guardians of university practice may appear to usher in dystopia but in our view this is necessary, desirable and unavoidable.

Another lesson to take to heart is that the gap between academics with little experience of administrative and policy responsibilities, and those in 'middle management' or in leadership positions, is potentially dangerous. 'Middle managers' are stuck deep in what Donald Schon would call, 'the swamp of practice' where decision-making is not clear-cut or easy to perform. Geoff Sharrock (2012) has identified four distinct domains that characterise this swamp and to which managers must attend: 
- programs: the diverse array of academic projects in student learning, research and third-stream activities that academic enterprises exist to pursue;

- people: the various professional groups who play direct or indirect roles in supporting and delivering academic programs and related functions of the enterprise;

- systems: the authority structures, technologies, policies and procedures that enable people to manage their programs and support functions effectively such as enrolling students, timetabling classes, paying staff, providing research facilities, and planning workloads and budgets; and

- strategy: plans to develop and maintain the capabilities needed to sustain the entire enterprise and its programs, people and systems.

These different domains are full of competing demands and argumentative voices. It is extremely difficult terrain to negotiate and there is precious little in the way of training (it's no surprise that the best book we have found on the topic is called Herding Cats (Garrett and Davies 2010). In our collective experience, academics who have not experienced middle management of some sort can have a limited understanding of what it takes to hold the university together. This is part of what leads to nostalgia for the golden age and produces the accusation that 'the administration' is full of pedants determined to burden overworked academics with administrivia (and here we single out Richard Hil's book, Whackademia (2012), for special mention). It contributes to an unhealthy polarisation of the academic workforce. The responsibility for opening the debate and bringing the passion for the core values of universities into the discussion about how to pay the bills should be shared by all of us. 
This text is taken from Through a Glass Darkly: The Social Sciences Look at the Neoliberal University, edited by Margaret Thornton, first published 2014, this version 2015 by ANU Press, The Australian National University, Canberra, Australia. 